\title{
FIREARM BACKGROUND CHECKS AS A PROXY FOR PURCHASES IN THE UNITED STATES: EXPLORING LINKAGES WITH ECONOMIC ACTIVITY
}

\author{
David Yerger, Indiana University of Pennsylvania, U.S.A. \\ Alexi Thompson, Indiana University of Pennsylvania, U.S.A.
}

dx.doi.org/10.18374/JIBE-21-1.4

\begin{abstract}
This paper contributes to the small, but developing, research literature investigating linkages between overall economic activity and firearms purchases related behavior in the U.S. market. Utilizing monthly data on national firearm background checks and national economic activity as measured by the Philadelphia Federal Reserve's national coincident index for two periods, January 1999 to October 2008 and November 2008 to December 2018, causal linkages between the two variables are examined. The data sample was split starting November 2008 to examine if the documented growth in partisanship over gun control issues since the November 2008 Presidential election has impacted linkages between actual economic activity and background checks. Based on Granger Causality tests, there is no evidence of national economic activity causing background checks in the early period, but in the later period there is strong evidence that economic activity Granger Causes background checks. Unsurprisingly, there is no evidence in either period of background checks Granger Causing economic activity. In addition to causality testing, national firearm background checks were forecast using a linear trend model with seasonal monthly dummies that permitted a change in the trend's slope coefficient as well as shifts in the seasonal monthly dummies for the later period. There was strong evidence that the seasonality effects have become more pronounced in the later period, especially for the Christmas buying season, and these effects offset a decline in the trend's slope coefficient. These strong seasonal effects are consistent with firearms buyers behaving as typical consumer goods purchasers.
\end{abstract}

Keywords: Firearm background checks, causality, firearm markets, United States 